\title{
Mutual Coupling Reduction of Two 2x1 Triangular-Patch Antenna Array Using a Single Neutralization Line for MIMO Applications
}

\author{
Erik FRITZ-ANDRADE ${ }^{1}$, Hildeberto JARDON-AGUILAR ${ }^{1}$, Jose Alfredo TIRADO-MENDEZ ${ }^{2}$ \\ ${ }^{1}$ Sección de Comunicaciones del Departamento de Ingeniería Eléctrica, Centro de Investigación y de Estudios Avanzados \\ (CINVESTAV), Av. IPN 2508, Col. San Pedro Zacatenco, C.P. 07360, Ciudad de México, México \\ ${ }^{2}$ Instituto Politécnico Nacional, SEPI-Electrical Engineering, Unidad Profesional "Adolfo López Mateos", Edif. Z, Acc. 4, \\ $2^{\circ}$ piso, Col. Lindavista, C.P. 07738, Ciudad de México, México \\ \{erik.fritz, hjardon\}@cinvestav.mx,jtiradom@ipn.mx
}

Submitted March 13, 2018 / Accepted July 16, 2018

\begin{abstract}
In this paper, a novel structure of two interlaced antenna arrays for MIMO applications is presented. It consists of two $2 \times 1$ triangular patch array antennas, which have all elements separated by a short distance among them $\left(0.22 \lambda_{0}\right)$, where mutual coupling can be very poor $\left(S_{21}=-7.81 \mathrm{~dB}\right)$. To overcome such weakness, a simple and efficient method is used: one neutralization line $(N L)$ is introduced to increase the decoupling between both ports, reaching up to $-29 \mathrm{~dB}$ at the central frequency, and below $-20 \mathrm{~dB}$ over a large bandwidth. The whole MIMO antenna array has dimensions of $1.56 \lambda_{0} \times 0.3 \lambda_{0}$ and has a gain of $9.11 \mathrm{dBi}$. Its diversity parameters describe it as a useful radiator for MIMO communications systems.
\end{abstract}

\section{Keywords}

Linear antenna arrays, microstrip antennas, mutual coupling, neutralization line, patch antennas

\section{Introduction}

The users of mobile communications systems demand higher data rates and more reliable radio links. The operators can offer these characteristics to the subscribers by exploiting Multiple Input Multiple Output (MIMO) Systems. MIMO communication systems can augment the spectral efficiency by using multiple antennas on both sides of the radio channel and enhance the wireless channel capacity of short- and long-distance links [1]. Such appealing features can be obtained only if the correlation between the ports of the MIMO antennas is kept low. When the distance between radiating elements is a small fraction of a wavelength $\left(\lambda_{0}\right)$, the electromagnetic interaction between certain regions of the antennas grows. Then, the mutual coupling between their ports is increased. A strong matching between nearby radiators increases the correlation between their ports and degrades the performance of a MIMO antenna system [2]. Besides, the current distribution of the MIMO antennas gets distorted, hence their radiation properties, namely gain, sidelobe level (SLL), pointing direction, half-power beamwidth, among others, are altered; also, the matching between the radiator and its own ports suffers disturbances.

The trend in the industry is getting smaller and more integrated devices, making difficult to keep their MIMO antennas away to each other. Many techniques intended to reduce the electromagnetic coupling between MIMO ports can be found in literature, for instance neutralization lines [3-5], EBG and metamaterial structures [6-8], modifications on the ground plane between the antennas [9], [10], coupling/decoupling networks [11], [12], parasitic scatterers [13], [14], and so on. It is noticeable that the efforts had been focused in one-element antennas, and far from abundant work had been done about improving the decoupling between antennas consisting of array of radiators.

Antenna arrays have several well-known advantages over one-element radiators, for instance pattern synthesis and high gain, making them appealable for long distance radio links because it is relatively easy to create an array of radiators, as many as the link budget requires, but constrained by the available space. MIMO communications systems that employ antenna array are as conceivable and pertinent as investigations about techniques to diminish the electromagnetic interaction among an ensemble of such antennas. For instance, in [15] two $2 \times 2$ rectangular-patch array antennas were decoupled by inserting between them two lines of mushroom EBG's. The article reports a reduction of their mutual coupling around $26 \mathrm{~dB}$. The separation between patches was $0.539 \lambda_{0}$, the footprint of the whole system of antennas was $1.92 \lambda_{0} \times 0.65 \lambda_{0}$, and the obtained gain was $7.5 \mathrm{~dB}$. Despite achieving a large reduction of the $\mathrm{S}_{21}$ parameter, the antenna system has a big footprint, small gain and involves the complicated implementation of the mushroom EBG's.

In this article a novel topology, detailed in Fig. 1, for a MIMO antenna system is proposed. Each antenna is con- 


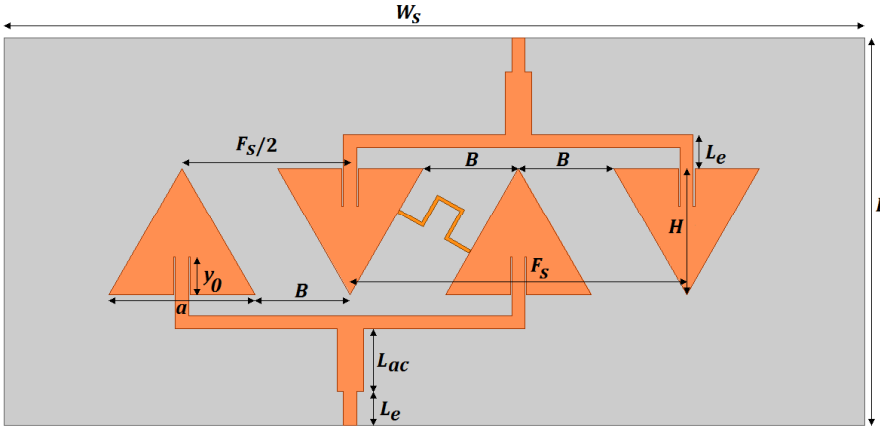

(a)

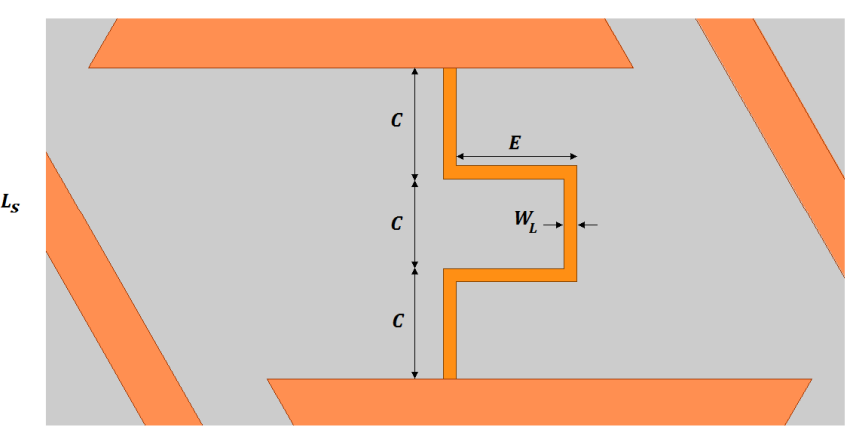

(b)

Fig. 1. Geometry and dimensions of the proposed antennas: (a) Top layer of the radiators, (b) detailed view of the neutralization line.

\begin{tabular}{|c|c|c|c|c|c|c|c|c|c|c|c|}
\hline $\boldsymbol{a}$ & $\boldsymbol{B}$ & $\boldsymbol{C}$ & $\boldsymbol{E}$ & $\boldsymbol{F}_{\mathrm{s}}$ & $\boldsymbol{H}$ & $\boldsymbol{L}_{\mathrm{ac}}$ & $\boldsymbol{L}_{\mathrm{e}}$ & $\boldsymbol{L}_{\mathrm{s}}$ & $\boldsymbol{W}_{\mathrm{L}}$ & $\boldsymbol{W}_{\mathrm{s}}$ & $\boldsymbol{y}_{\mathbf{0}}$ \\
\hline 42.4 & 27.74 & 8 & 9.355 & 97.89 & 36.72 & 18.09 & 10 & 112.9 & 1 & 250.42 & 11 \\
\hline
\end{tabular}

Tab. 1. Optimized dimensions of the proposed antenna arrays (unit: $\mathrm{mm}$ ).

formed by a $2 \times 1$ array of triangular patches, and both arrays are interlaced. Introducing one neutralization line (NL) between the innermost patches the $\mathrm{S}_{21}$ parameter is reduced to a proper level for current MIMO systems [5]. The decoupling method used in this work is easier to design and perform than the presented in [15], not affecting negatively the gain radiation pattern, and has a small footprint.

\section{Triangular Patch Antenna Array}

A microstrip patch uniform linear antenna array consists of an ensemble of such equidistant radiators, excited by a feed network. The separation among patches must impede the overlapping of the elements and must not be so large that allow the appearance of grating lobes into the visible space [16]. The patches of the array can have different forms, depending on the desired radiation characteristics; circular and rectangular are the most commonly used in literature. However, in recent years more attention had been focused on triangular patches [17], [18].

Equilateral triangle patch antennas show similar radiation features and bandwidth to the rectangular ones, but over a smaller footprint [17]. Their resonant frequency $f_{\mathrm{r}}$ is calculated by (1),

$$
f_{\mathrm{r}}=\frac{2 c}{3 a \sqrt{\varepsilon_{\mathrm{r}}}}
$$

where $c$ is the speed of light in the vacuum, $a$ is the edge length of the triangle, and $\varepsilon_{\mathrm{r}}$ is the relative permittivity of the chosen substrate [18]. By means of (1), a $2 \times 1$ triangular-patch array antenna, excited by a corporate feed for its operation at center frequency of $2.45 \mathrm{GHz}$ over a Taconic RF-35 0800 substrate $\left(\varepsilon_{\mathrm{r}}=3.5\right.$, height $\left.=2.032 \mathrm{~mm}\right)$ was designed, resulting in triangles of $a=43.6 \mathrm{~mm}$. The final dimensions of $a$ and $y_{0}$, indicated in Tab. 1, were tuned with a finite-element method software.
The optimal separation between array elements is determined by the intended application of the antenna, observing the radiation pattern on one plane and considering that such separation is inversely proportional to the halfpower beamwidth (HPBW) and directly proportional to the sidelobe level (SLL). A parametric analysis of the distance between centers of triangular patches $\left(F_{\mathrm{s}}\right)$ was performed, and the modification of the form of the radiation pattern in the E-plane versus $F_{\mathrm{s}}$ is displayed in Fig. 2. A good compromise between HPBW and SLL can be obtained for $0.7 \lambda_{0}<F_{\mathrm{s}}<0.8 \lambda_{0}$. For the next stages of this work, $F_{\mathrm{s}}$ was selected to be $0.8 \lambda_{0}=97.89 \mathrm{~mm}$. Thus, the $2 \times 1$ triangularpatch array antenna has a footprint of $140.29 \times 62.56 \mathrm{~mm}^{2}$ $\left(1.14 \lambda_{0} \times 0.51 \lambda_{0}\right)$, reaching a gain of $9.69 \mathrm{dBi}$, SLL of $-12.52 \mathrm{~dB}$ and front-to-back ratio (FBR) of $17.89 \mathrm{~dB}$.

For comparison reasons, the same parametric analysis was performed to an array of squared-patches. The results, which follow the trend reported in [19], are also shown in Fig. 2. The parasitic lobe levels are lower for the squaredpatch case. However, by using triangular patches the distance among them is larger than when using squared patches, which is more suitable for applying a decoupling method. In the following section it will be shown that $F_{\mathrm{s}}=0.8 \lambda_{0}$ is more suitable for this application than a minor value.

\section{Interlaced Antenna Arrays}

The squared-patch array presented in [15] occupies a large footprint, an undesired situation in mobile terminals. The occupied space can be reduced by interlacing two identical antenna arrays, with the same dimensions calculated in Sec. 2. The proposed topology, without a decoupling method, is presented in Fig. 3.

The definitive value of $F_{s}$ was determined by observing the $S_{21}$ parameter versus the inter-element distance for the interlaced arrays. Figure 4 displays this parametrization. 

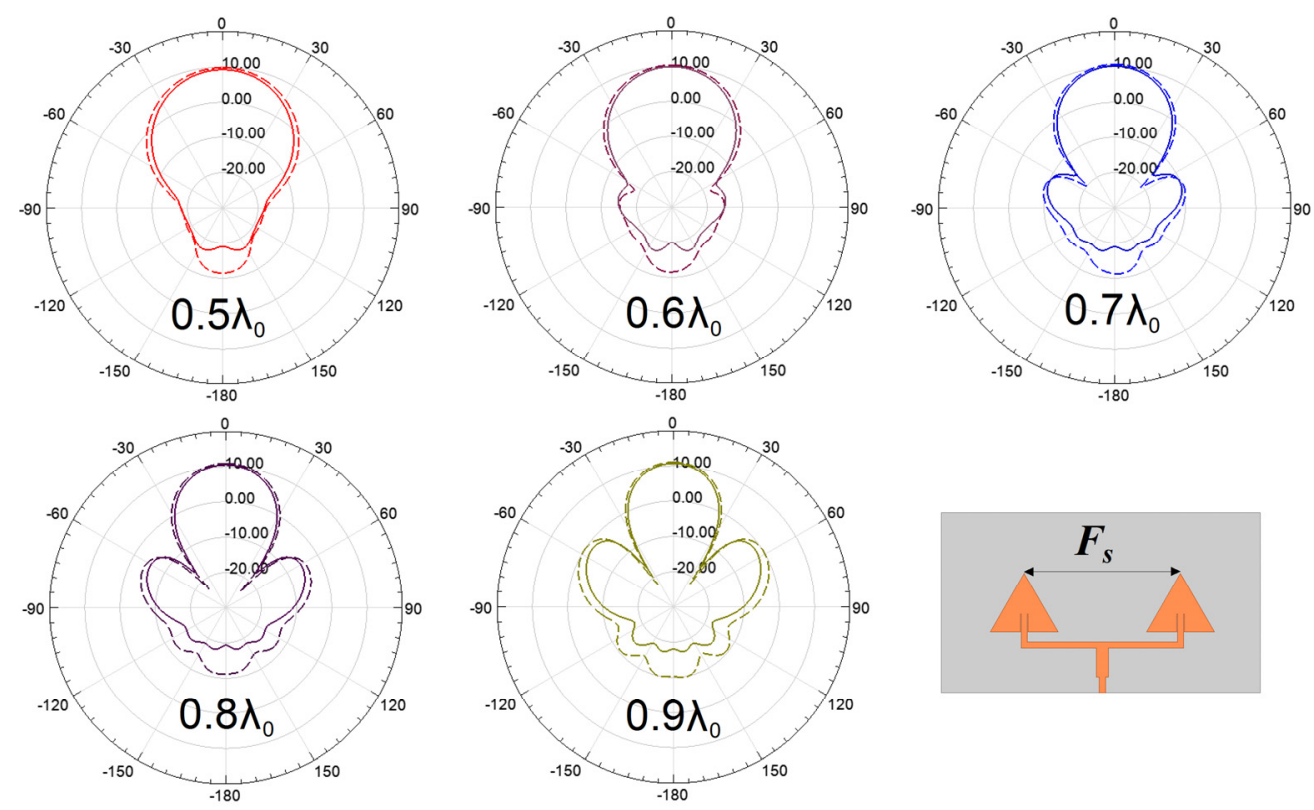

Fig. 2. Modification of the radiation pattern in the $\mathrm{E}$ plane for different separations of the patches $\left(F_{\mathrm{S}}\right)$ of a $2 \times 1$ array. Continuous line: squared patches; dashed line: triangular patches.
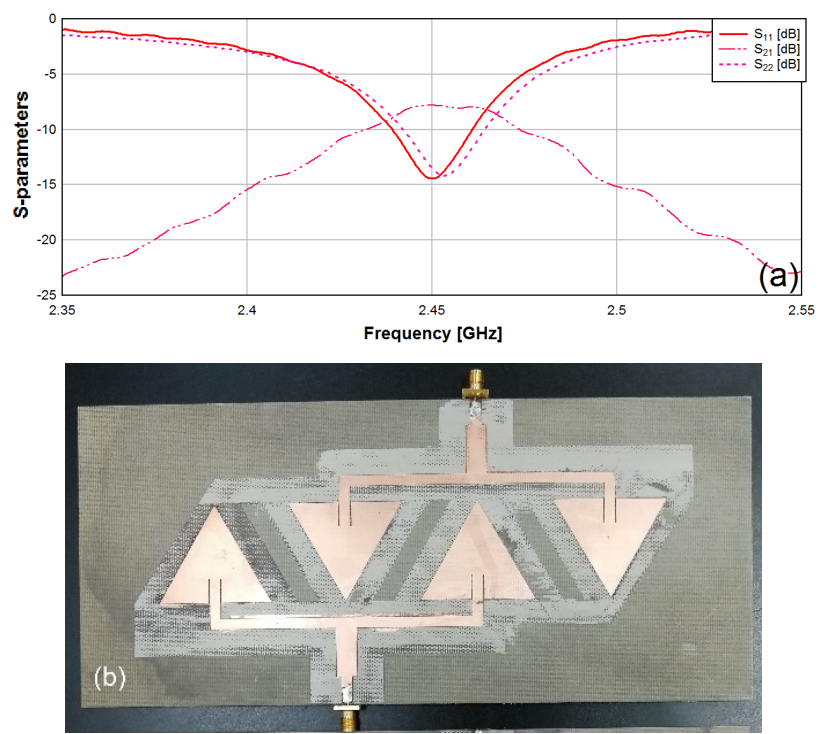

Fig. 3. (a) Measured S-parameters of two $2 \times 1$ triangular patch array antennas without any decoupling method. (b) Prototype measured with a Vector Network Analyzer.

It can be noticed that $F_{s}=0.8 \lambda_{0}$ is the minimum inter-element distance that does not perturb the resonant frequency and obtains a reasonable footprint.

Making $F_{S}=0.8 \lambda_{0}$, the separation between centers of adjacent patches, which does not belong to the same array, is $0.4 \lambda_{0}$. The distance between the closest vertices of different patches over the same axis (indicated as $B$ in Tab. 1) is $27.74 \mathrm{~mm}\left(0.22 \lambda_{0}\right)$. In Fig. 3, the measured $\mathrm{S}_{21}$ parameter reveals that the antennas are strongly coupled. However, a reduced rectangular footprint is obtained, being $1.56 \lambda_{0} \times 0.3 \lambda_{0}$

Besides the poor decorrelation between ports, the gain, the SLL and the pointing of the main beam are

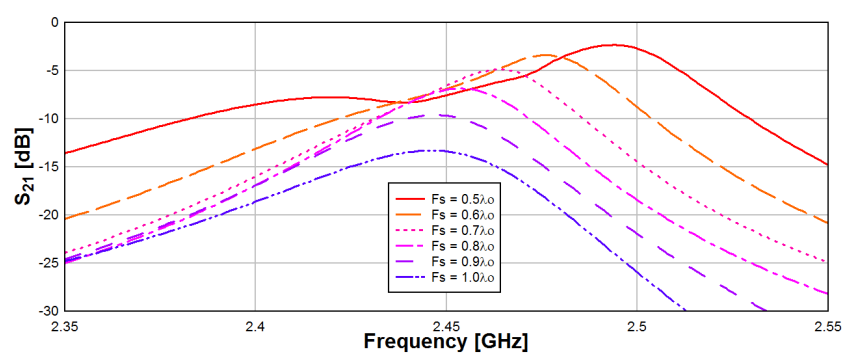

Fig. 4. Simulated $S_{21}$ parameter of two $2 \times 1$ interlaced arrays, by varying the $F_{\mathrm{s}}$ parameter.

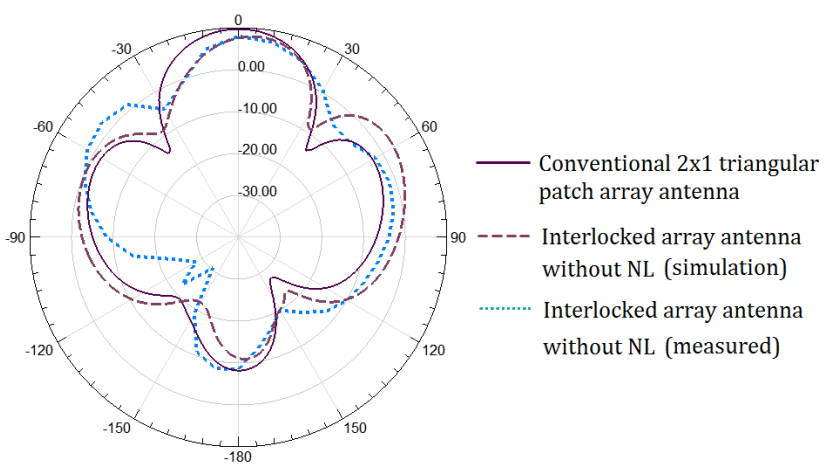

Fig. 5. Radiation pattern in E plane for a conventional $2 \times 1$ triangular-patch array antenna, compared to the simulated and measured radiation pattern of an interlaced array antenna.

slightly affected by the presence of the interlaced antenna, as can be observed in Fig. 5, which displays the simulated and measured radiation pattern of this interlaced topology, and the radiation pattern of a conventional $2 \times 1$ triangularpatch antenna array. The main beam direction is shifted by $10^{\circ}$, the SLL is increased up to $4 \mathrm{~dB}$ and null-filling occurs. The alterations in the radiation pattern are attributed to the modifications in the surface current, caused by the electromagnetic influence of the other nearby patches. 
Rectangular and even circular patches could fit in this interlaced topology. However, using the equilateral triangular form leaves more available space to apply one or more decoupling methods between the antennas, and reduces the possibility of overlapping the structures.

\section{Enhancing the Interlaced Arrays Performance by Using a Neutraliza- tion Line}

The neutralization line (NL), originally called "suspended line" [20], was presented to decouple two antennas with different but close central frequencies. Later, its application to decorrelate antennas of a MIMO communication system was discovered [21], [22]. Usually, those works place the conductor strip (with electric length of $180^{\circ}$ ) very close to the feed point of the antenna, or in points where the current reaches its maximum. The peak surface current of a triangular patch lies over a line which crosses the centroid of the radiator. The proposed interlaced geometry aligns the centroids of all the patches over the same line, an advantageous situation for etching the neutralization line. In the present work it was found that the effect of only one NL could attain an acceptable level of decoupling for two $2 \times 1$ interlaced array antennas.

A microstrip line that could introduce a change of phase of $180^{\circ}$ was designed and optimized in the FEM software. The design assumptions were: (1) there exists a pair of width and length that is optimum for a certain application [20], and (2) the distance between two adjacent patches was the maximum available space to collocate the NL. The width of the NL was fixed to $1 \mathrm{~mm}$, to make a compromise between the resolution of the CNC plotter, and to avoid creating a radiating line. According to Fig. 1, the straight line that connected the same point of two adjacent patches was $24.02 \mathrm{~mm}$ long (length $=3 C$ ), then the total length of the NL had to be divided between five segments: three of the same length $(24.02 \mathrm{~mm} / 3=C)$ and two with other length $(E)$. Using the conventional design equations of a microstrip [23], a straight line that introduces a change of phase of $180^{\circ}$ is $38.59 \mathrm{~mm}$, hence the total length of the NL $(3 C+2 E)$ should be close to that value but it is affected by the changes of trajectory of the line, the fringing fields from the patches, and the discontinuity of the transition line-patch. After the optimization process, the total length of the NL was $41.4 \mathrm{~mm}$.

Then the NL was placed between the innermost patches, as shown in Fig. 6. The simulator calculated small affectation on $S_{11}$ and $S_{22}$ parameters, and it was demonstrated by measuring the S-parameters of a prototype. The measured scattering parameters are displayed in Fig. 6.

By comparing Fig. 3 and Fig. 6, it can be noticed that the $S_{11}$ parameter was not strongly affected, the array antenna covered a $-10 \mathrm{~dB}$ bandwidth of $27 \mathrm{MHz}$ and the center frequency had a deviation of $12 \mathrm{MHz}$ to lower fre-
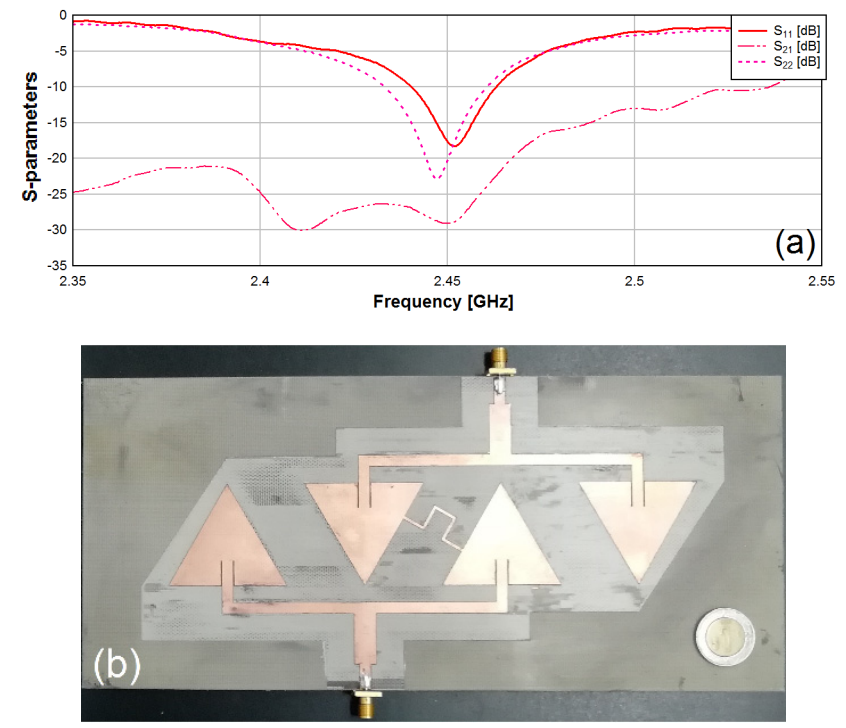

Fig. 6. (a) Measured S-parameters of two $2 \times 1$ triangular patch array antennas with the NL, (b) model and the measured prototype.

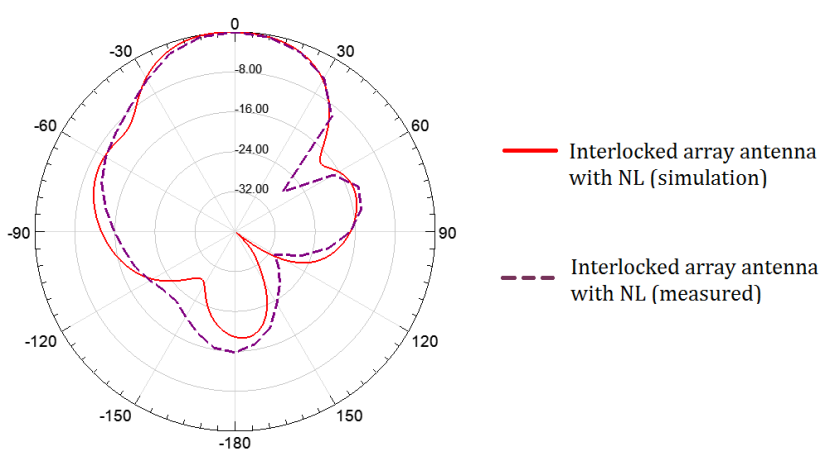

Fig. 7. Simulated (continuous) and measured (dashed) normalized radiation pattern of the neutralized arrays.

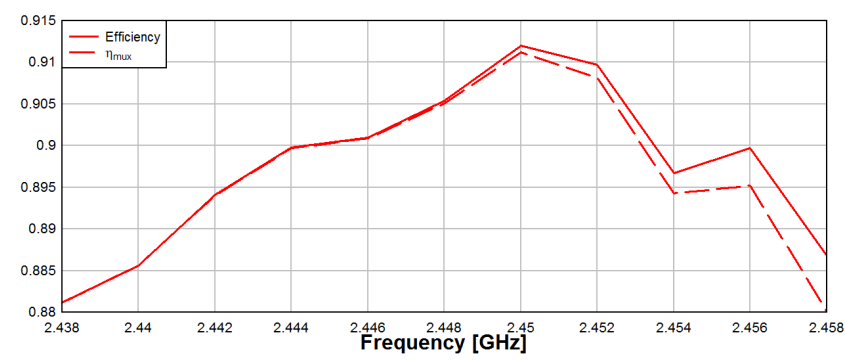

Fig. 8. Simulated radiation efficiency and multiplexing efficiency.

quencies but obtaining around $-30 \mathrm{~dB}$ at $2.45 \mathrm{GHz}$. The measured $\mathrm{S}_{21}$ parameter was effectively reduced from $-7.81 \mathrm{~dB}$ to $-29.06 \mathrm{~dB}$, a diminution of $21.25 \mathrm{~dB}$. Also, the $\mathrm{S}_{21}$ parameter remained under $-20 \mathrm{~dB}$ for all over the antenna $\mathrm{S}_{11}<-10 \mathrm{~dB}$ bandwidth.

Radiation pattern was also measured inside an anechoic chamber and compared with the results of the FEM simulator. Figure 7 displays the radiation pattern in the E-plane for simulated and measured data. The measured gain in boresight was $9.11 \mathrm{~dB}$, and $\mathrm{FBR}=15.85 \mathrm{~dB}$, then convergence between the simulated and measured results is 


\begin{tabular}{|c|c|c|c|c|c|c|c|c|c|c|}
\hline Paper & $\begin{array}{c}\text { Number of } \\
\text { radiating } \\
\text { elements }\end{array}$ & Footprint & $\begin{array}{c}\text { Decoupling } \\
\text { method }\end{array}$ & $\begin{array}{c}\mathbf{S}_{\mathbf{i j}} \\
\text { reduction } \\
{[\mathbf{d B}]}\end{array}$ & $\begin{array}{c}\text { Fractional } \\
\text { bandwidth } \\
{[\%]}\end{array}$ & $\begin{array}{c}\text { Realized } \\
\text { peak gain } \\
{[\mathbf{d B i}]}\end{array}$ & $\begin{array}{c}\text { Radiation } \\
\text { efficiency } \\
\text { (max.) }[\mathbf{\%}]\end{array}$ & $\begin{array}{c}\text { ECC } \\
\text { (max.) }\end{array}$ & $\begin{array}{c}\boldsymbol{\eta}_{\text {mux }} \\
\text { (max.) }\end{array}$ & $\begin{array}{c}\text { DG (max.) } \\
{[\mathbf{d B}]}\end{array}$ \\
\hline$[25]$ & 3 & $0.67 \lambda_{0} \times 0.29 \lambda_{0}$ & $\begin{array}{c}\text { Position of an- } \\
\text { tennas and slot }\end{array}$ & $\begin{array}{c}\text { Not } \\
\text { reported }\end{array}$ & $\begin{array}{c}>5,22 \\
\text { (dual band) }\end{array}$ & $\begin{array}{c}2.6,4.35 \\
\text { (dual band) }\end{array}$ & 65 & $<0.5$ & 60 & $\begin{array}{c}\text { Not } \\
\text { reported }\end{array}$ \\
\hline$[26]$ & 2 & $0.94 \lambda_{0} \times 0.3 \lambda_{0}$ & EBG structures & 7.01 & 4.48 & $\begin{array}{c}\text { Not } \\
\text { reported }\end{array}$ & Not reported & $\begin{array}{c}\text { Not } \\
\text { reported }\end{array}$ & $\begin{array}{c}\text { Not } \\
\text { reported }\end{array}$ & $\begin{array}{c}\text { Not } \\
\text { reported }\end{array}$ \\
\hline$[27]$ & 4 & $0.41 \times 0.41$ & $\begin{array}{c}\text { Metalized walls } \\
\text { and strips }\end{array}$ & 13 & $\begin{array}{c}1.6 \text { and } 0.7 \\
\text { (dual band) }\end{array}$ & $\begin{array}{c}2.7,2.85 \\
\text { (dual band) }\end{array}$ & 64 & 0.08 & $\begin{array}{c}\text { Not } \\
\text { reported }\end{array}$ & $\begin{array}{c}\text { Not } \\
\text { reported }\end{array}$ \\
\hline$[28]$ & 2 & $0.91 \lambda_{0} \times 0.6 \lambda_{0}$ & $\begin{array}{c}\text { Metamaterial } \\
\text { (modified SRR) }\end{array}$ & $\begin{array}{c}\text { Not } \\
\text { reported }\end{array}$ & 115 & $\begin{array}{c}\text { Not } \\
\text { reported }\end{array}$ & $>90$ & 0.003 & $\begin{array}{c}\text { Not } \\
\text { reported }\end{array}$ & 9.8 \\
\hline$[29]$ & 4 & $1.2 \lambda_{0} \times 1.2 \lambda_{0}$ & EBG structures & 20 & 3.5 & 7.1 & 90 & 0.004 & $\begin{array}{c}\text { Not } \\
\text { reported }\end{array}$ & $\begin{array}{c}\text { Not } \\
\text { reported }\end{array}$ \\
\hline $\begin{array}{c}\text { This } \\
\text { work }\end{array}$ & 4 & $1.56 \lambda_{0} \times 0.3 \lambda_{0}$ & $\begin{array}{c}\text { Neutralization } \\
\text { line }\end{array}$ & 21.25 & 1.02 & 9.11 & 91 & 0.015 & 90.9 & 9.9 \\
\hline
\end{tabular}

Tab. 2. Comparison among the results obtained in this work and recent papers.

observed. The simulated radiation efficiency of each antenna array, including the neutralization line, varies from $88 \%$ to $91 \%$ in the $-10 \mathrm{~dB}$ bandwidth, and is displayed in Fig. 8.

The proposed topology and the presented method of decoupling both array antennas obtain similar or better results compared to those shown in [5], [15], achieving higher gain with smaller footprint, using less radiating elements, but with an easier design and implementation.

\section{MIMO Performance}

The effectivity of a set of antennas could be determined by their individual antenna parameters, but there are specific metrics that point out univocally if an array is suitable for a certain MIMO application. Under some circumstances, many of them can be derived from their S-parameters.

The Envelope Correlation Coefficient (ECC) indicates how independent the radiation patterns of the antennas in a system are. For good diversity/MIMO performance, $E C C<0.5$ [24]. If the antennas have high radiation efficiency, the ECC can be approximated by (2):

$$
E C C=\frac{\left|S_{11}^{*} S_{12}+S_{21}^{*} S_{22}\right|^{2}}{\left(1-\left|S_{11}\right|^{2}-\left|S_{21}\right|^{2}\right)\left(1-\left|S_{22}\right|^{2}-\left|S_{12}\right|^{2}\right)} .
$$

Using (2), the value of ECC was determined to be below 0.015 across the $-10 \mathrm{~dB}$ bandwidth for the proposed neutralized antenna system, getting a minimum value of $8.8 \times 10^{-5}$. ECC versus frequency is displayed in Fig. 9 .

The multiplexing efficiency $\eta_{\text {mux }}$ is the parameter that relates the total efficiency of both antennas and their correlation [25]. It is described by (3)

$$
\eta_{\text {mux }}=\sqrt{\eta_{1} \eta_{2}(1-E C C)}
$$

where $\eta_{1}$ and $\eta_{2}$ stand for the total efficiency of antenna 1 and 2, respectively. Using (3), minimum value of $87 \%$ and maximum of $90.9 \%$ is obtained for the presented prototype.

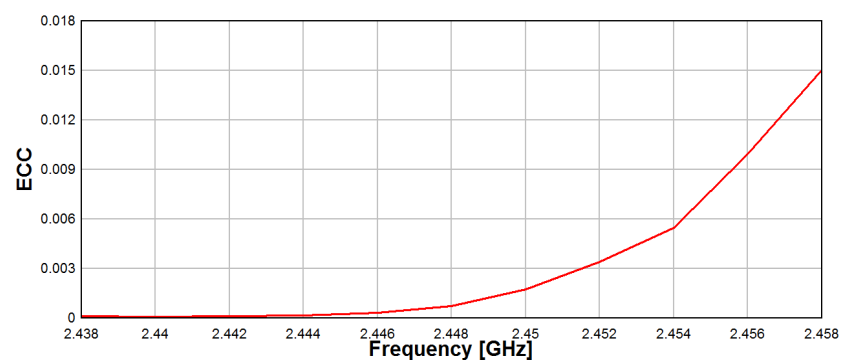

Fig. 9. Simulated Envelope Correlation Coefficient.

The diversity gain (DG) can be used to describe the gain enhancement of a multi-antenna system in a combined signal over time-averaged signal-to-noise ratio [24]. A Finite Difference Time Domain (FDTD) software was used to calculate the DG of the interlaced and neutralized antenna arrays. A constant value of $D G=9.9 \mathrm{~dB}$ was determined.

A comparison between the results presented in this paper, and the ones shown in other works can be observed in Tab. 2.

\section{Conclusions}

A novelty setting of two interlaced antenna arrays for MIMO applications having small footprint is proposed, with enough space for applying decoupling techniques between the radiators. A study about the influence of their inter-element distance over their radiation patterns and Sparameters was conducted.

Only one neutralization line was used to decouple two $2 \times 1$ interlaced array antennas up to $S_{21}=-29.06 \mathrm{~dB}$, i. e. a diminution of $21.25 \mathrm{~dB}$, maintaining their $-10 \mathrm{~dB}$ bandwidth, gain, center frequency and general form of the radiation pattern. These results are competitive with those exhibited by neutralization lines used to decouple narrowband radiators, and simultaneously getting larger gain and smaller footprint, including all its main advantages over other decoupling methods: ease of design and implementation. 
The results were tested by measuring the electrical properties of two prototypes with and without the decoupling method, and there was a strong correlation between the simulated and measured ones.

Different investigations still in progress are needed to determine a general method to decouple $N \times 1$ or even $N \times M$ interlaced arrays.

\section{References}

[1] VAUGHAN, G., ANDERSEN, J. B. Antenna diversity in mobile communications. IEEE Transactions on Vehicular Technology, 1987, vol. 36, no. 4, p. 149-172. DOI: 10.1109/T-VT.1987.24115

[2] ZHAO, J., LI, Y., SUN, G. The effect of mutual coupling on capacity of 4-element squared antenna array MIMO systems. In IEEE 5th International Conference on Wireless Communications, Networking and Mobile Computing. Beijing (China), 2009, p. 1-4. DOI: 10.1109/WICOM.2009.5301788

[3] ZHANG, S., PEDERSEN, G. F. Mutual coupling reduction for UWB MIMO antennas with a wideband neutralization line. IEEE Antennas and Wireless Propagation Letters, 2015, vol. 15 , p. 166-169. DOI: 10.1109/LAWP.2015.2435992

[4] ABDULlAH, M., BAN, Y.-L., KANG, K., et al. Compact fourport MIMO antenna system at $3.5 \mathrm{GHz}$. In 2017 IEEE 2nd Advanced Information Technology, Electronic and Automation Control Conference (IAEAC). Chongqin (China), 2017. DOI: 10.1109/IAEAC.2017.8054098

[5] NIRMAL, P., NANDGAONKA, A. B., NALBALWA, S. L. A MIMO antenna: Study on reducing mutual coupling and improving isolation. In IEEE International Conference on Recent Trends in Electronics Information Communication Technology (RTEICT). Bagalore (India), May, 2016, p. 1736-1740. DOI: 10.1109/RTEICT.2016.7808131

[6] LIU, Z., SHI, Y., SHI, D., GAO, Y. Mutual coupling reduction of a $2.6 \mathrm{GHz}$ dual-element MIMO antenna system with EBG structures. In 2014 XXXIth URSI General Assembly and Scientific Symposium (URSI GASS). Beijing (China), 2014, p. 1-4. DOI: 10.1109/URSIGASS.2014.6929527

[7] RADHI, A. H., AZIZ, N. A., NILAVALAN, R., et al. Mutual coupling reduction between two PIFA using uni-planar fractal based EBG for MIMO application. In 2016 Loughborough Antennas \& Propagation Conference (LAPC). Loughborough (United Kingdom), 2016, p. 1-5. DOI: 10.1109/LAPC.2016.7807564

[8] FARAHANI, M., ZAID, J., DENIDNI, T. A., AKBARI, M., et al. Mutual coupling reduction in millimeter-wave MIMO dielectric resonator antenna using metamaterial polarization rotator wall. In 2017 IEEE International Symposium on Antennas and Propagation \& USNC/URSI National Radio Science Meeting. San Diego (USA), 2017, p. 1261-1262. DOI: 10.1109/APUSNCURSINRSM.2017.8072673

[9] LI, Q., FERESIDIS, A. P. Reduction of mutual coupling between compact MIMO antennas arrays. In 2010 Loughborough Antennas \& Propagation Conference. Loughborough (United Kingdom), 2010, p. 277-280. DOI: 10.1109/LAPC.2010.5666191

[10] SOLTANI, S., LOTFI, P., MURCH, R. D. Design of compact dual-band dual-port WLAN MIMO antennas using slots. In 2015 IEEE International Symposium on Antennas and Propagation \& USNC/URSI National Radio Science Meeting. Vancouver (Canada), 2015, p. 924-925. DOI: 10.1109/APS.2015.7304849

[11] ELFERGANI I. T. E., HUSSAINI, A. S., RODRIGUEZ, J., et al. Compact and closely spaced tunable printed F-slot multiple-input- multiple-output antenna system for portable wireless applications with efficient diversity. IET Science, Measurement \& Technology, 2014, vol. 8, no. 6, p. 359-369. DOI: 10.1049/iet-smt.2013.0276

[12] TAluJA, P. S., HUGHES, B. L. Diversity limits of compact broadband multi-antenna systems. IEEE Journal on Selected Areas in Communications, 2013, vol. 31, no. 2, p. 326-337. DOI: 10.1109/JSAC.2013.130219

[13] FARSI, S., ALIAKBARIAN, H., SCHREURS, D., et al. NAUWELAERS B., et al. Mutual coupling reduction between planar antennas by using a simple microstrip U-section. IEEE Antennas and Wireless Propagation Letters, 2012, vol. 11, p. 1501-1503. DOI: 10.1109/LAWP.2012.2232274

[14] MAK, A. C. K., ROWELL, C. R., MURCH, R. D. Isolation enhancement between two closely packed antennas. IEEE Transactions on Antennas and Propagation, 2008, vol. 56, no. 11, p. 3411-3419. DOI: 10.1109/TAP.2008.2005460

[15] GHALOUA, A., ZBITOU, J., LATRACH, M., EL ABDELLAOUI L., et al. Mutual coupling reduction and miniaturization arrays antennas using new structure of EBG. In 2017 International Conference on Wireless Technologies, Embedded and Intelligent Systems (WITS). Fez (Morocco), 2017, p. 1-5. DOI: 10.1109/WITS.2017.7934593

[16] BALANIS, C. A. Antenna Theory: Analysis and Design. $4^{\text {th }}$ ed. New Jersey (USA): John Wiley \& Sons, 2016 ISBN: 9781118642061

[17] KHRAISAT, Y. S. H., OLAIMAT, M. M. Comparison between rectangular and triangular patch antennas array. In 2012 19th International Conference on Telecommunications (ICT). Jounieh (Lebanon), 2012, p. 1-5. DOI: 10.1109/ICTEL.2012.6221265

[18] HANNACHI, C., TATU, S. O. Performance comparison of $60 \mathrm{GHz}$ printed patch antennas with different geometrical shapes using miniature hybrid microwave integrated circuits technology. IET Microwaves, Antennas \& Propagation, 2017, vol. 11, no. 1, p. 106-112. DOI: 10.1049/iet-map.2015.0720

[19] LEVINE, E., MALAMUD, G., SHTRIKMAN, S., TREVES, D. A study of microstrip array antennas with the feed network. IEEE Transactions on Antennas and Propagation, 1989, vol. 37, no. 4, p. 426-434. DOI: $10.1109 / 8.24162$

[20] DiAllO, A., LUXEY, C., LE THUC, P., STARAJ, R., et al. Study and reduction of the mutual coupling between two mobile phone PIFAs operating in the DCS1800 and UMTS bands. IEEE Transactions on Antennas and Propagation, 2006, vol. 54, no. 11, p. 3063-3074. DOI: 10.1109/TAP.2006.883981

[21] LIN, S.-Y., LIU, I.-H. Small inverted-U loop antenna for MIMO applications. Progress In Electromagnetics Research C, 2013, vol. 34, p. 69-84. DOI: 10.2528/PIERC12082901

[22] MALVIYA, L., PANIGRAHI, R. K., KARTIKEYAN, M. V. MIMO antennas with diversity and mutual coupling reduction techniques: a review. International Journal of Microwave and Wireless Technologies, May 2017, vol. 9, no. 8, p. 1763-1780. DOI: $10.1017 / \mathrm{S} 1759078717000538$

[23] HONG, J.-S., LANCASTER, M. J. Microstrip Filters for RF/Microwave Applications. New York (USA): John Wiley \& Sons, 2001, p. 79-81. ISBN: 0-89006-513-6

[24] CHEN, Z. N., LIU, D., NAKANO, H., QING, X., ZWICK, TH. (eds). Handbook of Antenna Technologies. $1^{\text {st }}$ ed. Singapore (Singapore): Springer Singapore, 2016. ISBN: 9789814560436

[25] ANDÚJAR, A. ANGUERA, J. MIMO multiband antenna system combining resonant and nonresonant elements. Microwave and Optical Technology Letters, 2014, vol. 56, no. 5, p. 1076-1084. DOI: $10.1002 / \mathrm{mop} .28282$

[26] BHAVARTHE, P. P., RATHOD, S. S., REDDY, K. T. V. Mutual coupling reduction in patch antenna using Electromagnetic Band 
Gap (EBG) structure for IoT application. In 2018 International Conference on Communication Information and Computing Technology (ICCICT). Mumbai (India), February 2018, p. 1-4. DOI: 10.1109/ICCICT.2018.8325867

[27] BOUKARKAR, A., LIN, X. Q., JIANG, Y., et al. A miniaturized extremely close-spaced four-element dual-band MIMO antenna system with polarization and pattern diversity. IEEE Antennas and Wireless Propagation Letters, 2018, vol. 17, no. 1, p. 134-137. DOI: 10.1109/LAWP.2017.2777839

[28] KHARCHE, S., REDDY, G. S., MUKHERJEE, J., GUPTA, R. Mutual coupling reduction by using tilted variable length SRR like structure in UWB MIMO antennas. In 2017 IEEE International Symposium on Antennas and Propagation \& USNC/URSI National Radio Science Meeting. San Diego (USA), July 2017, p. 2285-2286. DOI: 10.1109/APUSNCURSINRSM.2017.8073185

[29] ZHAI, G., CHEN, Z. N., QING, X. Mutual coupling reduction of a closely spaced four-element MIMO antenna system using discrete mushrooms. IEEE Transactions on Microwave Theory and Techniques, October 2016, vol. 64, no. 10, p. 3060-3067. DOI: 10.1109/TMTT.2016.2604314

\footnotetext{
About the Authors ...

Erik FRITZ-ANDRADE (corresponding author) was born in México. He received his B.S. degree in Communications and Electronic Engineering, M.Sc. degree in Electrical Engineering from the National Polytechnic Institute
}

of Mexico in 2013 and 2016, respectively. Today he is pursuing his $\mathrm{Ph} . \mathrm{D}$. degree in Telecommunications in CINVESTAV-IPN, Mexico. His research interests include electromagnetic compatibility, antennas for communication systems and other microwave devices.

Hildeberto JARDÓN-AGUILAR was born in Tenancingo, Mexico, in 1949. He received the B.S. degree in Electrical Engineering from the National Polytechnic Institute of Mexico, and the Ph.D. degree in Radio Systems from the Moscow Technical University of Telecommunications and Informatics, Moscow, Russia. He is a Full Professor at the Center of Research and Advanced Studies, CINVESTAV-IPN, Mexico, since 1985. His research interests include analysis of nonlinearities in RF and microwave circuits, electromagnetic compatibility and photonic systems.

José Alfredo TIRADO-MÉNDEZ was born in Mexico City, Mexico. He received the B.S. degree in Electronics and Digital Systems from the Metropolitan Autonomous University (UAM)-Azcapotzalco, Mexico City, in 1999, and the M.Sc. and Ph.D. degrees in Telecommunications from the Center of Research and Advanced Studies, CINVESTAV-IPN, Mexico, in 2001 and 2008, respectively. His research interests are electromagnetic compatibility and nonlinearities as well as RF and microwave circuit design, patch antennas and microstrip filters. 